\title{
Peroxiredoxin 1 has an anti-apoptotic role via apoptosis signal-regulating kinase 1 and p38 activation in mouse models with oral precancerous lesions
}

\author{
JIANFEI ZHANG, XINYING JING, WENWEN NIU, MIN ZHANG, \\ LIHUA GE, CONGCONG MIAO and XIAOFEI TANG
}

\begin{abstract}
Beijing Institute of Dental Research, Beijing Stomatological Hospital and School of Stomatology, Beijing Key Laboratory, Capital Medical University, Beijing 100050, P.R. China
\end{abstract}

Received March 17, 2015; Accepted April 8, 2016

DOI: $10.3892 / 01.2016 .4659$

\begin{abstract}
Peroxiredoxin 1 (Prx1) is important in the protection of cells from oxidative damage and the regulation of cell proliferation and apoptosis. Prx1 is overexpressed in oral precancerous lesions of oral leukoplakia (OLK) and oral cancer; however, the association between Prx1 expression and OLK pathogenesis remains unknown. The present study investigated the role of Prx1 and its molecular mechanisms in oxidative stress-induced apoptosis during the pathogenesis of OLK. Wild-type and Prx1 knockout mice were treated with $50 \mu \mathrm{g} / \mathrm{ml}$ 4-nitroquinoline-1-oxide (4NQO) or $4 \mathrm{NQO}+\mathrm{H}_{2} \mathrm{O}_{2}$ for 16 weeks to establish mouse models with tongue precancerous lesions. Apoptotic cells were detected using terminal deoxynucleotidyl transferase dUTP nick-end labeling assay. The expression of Prx1, apoptosis signal-regulating kinase 1 (ASK1), phosphor-ASK1, p38 and phosphor-p38 was analyzed using immunohistochemical staining, and their mRNA expression levels were evaluated by reverse transcription quantitative polymerase chain reaction. The present results demonstrated that $4 \mathrm{NQO}$ or $4 \mathrm{NQO}+\mathrm{H}_{2} \mathrm{O}_{2}$ induced the development of tongue precancerous lesions in Prx1 knockout and wild-type mice. Prx1 was overexpressed in tongue precancerous lesions compared with normal tongue mucosa. There was a significant decrease in the degree of moderate or severe epithelial dysplasia, and mild epithelial dysplasia was clearly elevated, in Prx1 knockout mice treated with 4NQO $+\mathrm{H}_{2} \mathrm{O}_{2}$ compared with wild-type mice treated with $4 \mathrm{NQO}+\mathrm{H}_{2} \mathrm{O}_{2}$. Prx1 suppressed apoptosis and upregulated phosphor-ASK1 and phosphor-p38 expression in tongue precancerous lesions. The present results suggest that Prx1 suppresses oxidative
\end{abstract}

Correspondence to: Professor Xiaofei Tang, Beijing Institute of Dental Research, Beijing Stomatological Hospital and School of Stomatology, Beijing Key Laboratory, Capital Medical University, 4 Tiantan Xili, Dongcheng, Beijing 100050, P.R. China

E-mail: tangxf0401@sohu.com

Key words: oral leukoplakia, Prx1 knockout mice, oxidative stress, apoptosis, ASK1, p38 stress-induced apoptosis via the ASK1/p38 signalling pathway in mouse tongue precancerous lesions. In conclusion, Prx1 and $\mathrm{H}_{2} \mathrm{O}_{2}$ have a coordination role in promoting the progression of tongue precancerous mucosa lesions. The present findings provide novel insight into Prx1 function and the mechanisms of Prx1 in OLK pathogenesis.

\section{Introduction}

Oral leukoplakia (OLK) is the most common oral precancerous lesion, with a global prevelance of $1 \%$ (1) and a malignant transformation rate of $0.13-17 \%$ (2). Following OLK transformation to oral cancer, the 5- and 10-year survival rates are 59 and $48 \%$, respectively (3). Currently, the pathogenesis of OLK is unclear. Numerous studies have demonstrated that OLK is closely associated with smoking, drinking and betel chewing (4-8). Tobacco, betel nut and alcohol all increase the expression of the oxidant $\mathrm{H}_{2} \mathrm{O}_{2}$ in saliva and oral mucosal cells $(9,10)$, and $\mathrm{H}_{2} \mathrm{O}_{2}$ expression at a high level may result in oxidative damage of DNA and activation of apoptotic genes, thus inducing apoptosis of cells (11-13). Reactive oxygen species (ROS) is a collective term that describes $\mathrm{O}_{2}$-derived non-radical species, including $\mathrm{H}_{2} \mathrm{O}_{2}$, and $\mathrm{O}_{2}$-derived free radicals, such as superoxide anion, hydroxyl and peroxyl free radicals. At physiological low levels, ROS functions as redox messengers in intracellular signaling and regulation. However, excessive ROS induce oxidative modification of macromolecules, inhibit protein functions and promote apoptosis of cells (14).

Peroxiredoxins (Prxs) are thio-specific antioxidant enzymes, and may be induced by several types of oxidative stress conditions. They are associated with neutralizing cellular hydroperoxides, which protect cells from oxidative damage. Prxs are often identified in mammals, yeast and bacteria, which are classified as 1-cys Prx and 2-cys Prx on the basis of one or two conserved cysteine residues. Peroxiredoxin 1 (Prx1), as an important member of Prxs, has two conserved cysteine residues (15). Current evidence suggests that Prx1, as a simple peroxidase, initiates the mechanistic switch from peroxidase to chaperone function, meaning that it is closely associated with a variety of biological processes including cell proliferation, differentiation and apoptosis (16). 
Yanagawa et al $(17,18)$ have identified that an overexpression of Prx1 is significantly associated with the recurrence of oral squamous cell carcinoma (OSCC). Previous studies by the present authors have confirmed that Prx1 expression and 8-hydroxy-2'-deoxyguanosine (8-OHdG) expression levels are elevated in human OLK tissues, and an increase in 8-OHdG is consistent with the expression of Prx1 (19). This result indicates that there is a significant association between Prx 1 and oxidative damage in the progression of OLK. Whether Prx 1 is important in OLK remains unknown, and the mechanism associated with Prx1 and apoptosis or oxidative stress remains unclear.

Apoptosis signal-regulating kinase 1 (ASK1) is a serine-threonine protein kinase that functions as a mitogen-activated protein kinase (MAPK), which activates c-Jun N-terminal kinase (JNK) and p38 MAPK signaling cascades. ASK1 may be activated by various stresses and is critical in the regulation of signaling in response to oxidative stress, which is a major contributor to cell death (20-22). Kim et al (23) have demonstrated that Prx1 plays a negative role in regulating ASK1-induced apoptosis. However, to the best of our knowledge, there is no evidence that reveals similar results in vivo.

In the present study, 4-nitroquinoline-1-oxide (4NQO) was used to establish a precancerous lesion model in wild-type and Prx1 knockout mice, to investigate the apoptotic role of Prx1 in oral precancerous lesions based on the hypothesis that Prx 1 may mediate the ASK1/p38 signalling pathway. In addition, the effect of oxidative stress on Prx1 and apoptosis in oral precancerous lesions was also determined. Understanding the molecular mechanisms of Prx1 involved in the initiation and progression to malignancy may benefit methods for the prognosis and treatment of oral precancerous lesions.

\section{Materials and methods}

Experimental animals. A total of 50 wild-type C57BL/6 mice (Vital River Laboratory Animal Technology Co., Ltd., Shenzhen, China) and 50 Prx1 knockout mice, which had been previously established (24), aged 6-8 weeks old, were used in the present study. All the animals were kept in accordance with institutional guidelines in specific pathogen free units at $24 \pm 2^{\circ} \mathrm{C}$ room temperature with $40-60 \%$ humidity, in a 14 day light/10 day dark cycle with freely accessible water food. The experimental protocol for the present study was approved by the local Ethical Committee for Animal Use. The experimental mice were randomly divided into six groups that underwent various treatments as follows: Wild-type control $(n=10)$, treatment with vehicle (distilled water); wild-type 4NQO group $(\mathrm{n}=20)$, treatment with $50 \mu \mathrm{g} / \mathrm{ml}$ 4NQO (Sigma-Aldrich, St. Louis, MO, USA) every day; wild-type $4 \mathrm{NQO}+\mathrm{H}_{2} \mathrm{O}_{2}$ group $(\mathrm{n}=20)$, treatment with $50 \mu \mathrm{g} / \mathrm{ml}$ 4NQO every day and $3 \% \mathrm{H}_{2} \mathrm{O}_{2}$ smeared on tongue mucosa three times a week; Prx1 knockout control group $(\mathrm{n}=10)$, treatment with vehicle (distilled water); Prx1 knockout 4NQO group ( $\mathrm{n}=20)$, treatment with $50 \mu \mathrm{g} / \mathrm{ml}$ $4 \mathrm{NQO}$ every day; and Prx1 knockout $4 \mathrm{NQO}+\mathrm{H}_{2} \mathrm{O}_{2}$ group $(\mathrm{n}=20)$, treatment with $50 \mu \mathrm{g} / \mathrm{ml} 4 \mathrm{NQO}$ every day and $3 \%$ $\mathrm{H}_{2} \mathrm{O}_{2}$ smeared on tongue mucosa three times a week. All these treatments lasted for 16 weeks. The mice were euthanized and the tongues were resected and immediately stored in liquid nitrogen for future molecular/cellular analysis, or in formalin for the preparation of paraffin-embedded tissue blocks.

Terminal deoxynucleotidyl transferase dUTP nick-end labeling (TUNEL) assay. Apoptosis was examined using In Situ Cell Death Detection kit, POD (Roche Diagnostics, Mannheim, Germany), according to the manufacturer's protocol. The paraffin-embedded tissues were baked at $65^{\circ} \mathrm{C}$ for $1 \mathrm{~h}$, de-waxed using xylene and gradually dehydrated with $100,95,90,80$ and $70 \%$ ethanol. The specimens were washed twice with phosphate-buffered saline (PBS) for 5 min each wash, treated with proteinase $\mathrm{K}$ solution $(10 \mathrm{mM}$ Tris- $\mathrm{HCl}$ with $20 \mu \mathrm{g} / \mathrm{ml}$ proteinase K; Merck Millipore, Darmstadt, Germany), incubated at $37^{\circ} \mathrm{C}$ for $15 \mathrm{~min}$, and washed twice with PBS for 5 min each wash. Dry specimens were treated with $50 \mu \mathrm{l}$ TUNEL reaction mixture (dilution, 1:5), covered with a cover slip, hydrated in light-free conditions and incubated at $37^{\circ} \mathrm{C}$ for $60 \mathrm{~min}$. The specimens were subsequently washed three times with PBS for 5 min each wash, and dry specimens were treated with $50 \mu \mathrm{l}$ converter-POD, covered with a cover slip, hydrated in light-free conditions, incubated at $37^{\circ} \mathrm{C}$ for $60 \mathrm{~min}$, and washed three times in PBS for $5 \mathrm{~min}$ each wash. Finally, the specimens were subjected to incubation with freshly prepared 3,3'-diaminobenzidine (DAB) solution for $10 \mathrm{~min}$, hematoxylin staining, soaking twice in anhydrous ethanol for $5 \mathrm{~min}$ and xylene for 2 min and mounting with neutral gum.

Immunohistochemical staining. The paraffin-embedded mouse tongue specimens $(4 \mu \mathrm{m})$ were de-paraffinized and hydrated using gradient alcohol, and rinsed with PBS. Antigen retrieval for Prx1, ASK1, phosphor-ASK1 and p38 was conducted with a citrate buffer $(\mathrm{pH}=6.0)$ in a microwave oven, and for phosphor-p38 with an EDTA buffer. Subsequently, the sections were blocked with $3 \% \mathrm{H}_{2} \mathrm{O}_{2}$ at room temperature for $15 \mathrm{~min}$ to remove the endogenous peroxidase and incubated in $10 \%$ goat serum (Beijing Zhongshan Jinqiao Biotechnology Co., Ltd., Beijing, China) as a blocking solution at $37^{\circ} \mathrm{C}$ for $30 \mathrm{~min}$. The specimens were incubated with the following primary antibodies: Polyclonal rabbit anti-Prx1 (dilution, 1:5,000; \#ab41906; Abcam, Cambridge, MA, USA), polyclonal rabbit anti-ASK1 (dilution, 1:200; \#bs-1425R; Bioss, Inc., Beijing, China), monoclonal rabbit anti-phosphor-ASK1 (dilution, 1:400; \#GTX50229; GeneTex, Inc., Irvine, CA, USA), p38 (dilution, 1:800; \#bs-0637R; Bioss, Inc.) and phosphor-p38 (dilution, 1:200; \#4631; Cell Signaling Technology, Inc., Danvers, MA, USA) at $4^{\circ} \mathrm{C}$ overnight. The specimens were incubated with biotinylated secondary IgG antibody (from the MaxVision ${ }^{\mathrm{TM}}$ HRP-Polymer anti-Mouse IHC kit; Fuzhou Maixin Biotech Co., Ltd., Fuzhou, China) at $37^{\circ} \mathrm{C}$ for $30 \mathrm{~min}$, and then visualized using DAB staining for 2-5 min. The specimens were subjected to Mayer's hematoxylin staining, dehydration and mounting. For the negative control, PBS was used in place of a primary antibody. Hepatocellular carcinoma tissue and small intestine tissue were used as the positive controls for Prx1 and p38, respectively, while breast carcinoma tissue was used as the positive control for ASK1, phosphor-ASK1 and phosphor-p38.

For evaluating the apoptosis level and the expression of phosphor-p38, the cells with positive staining were 
determined by counting the stained cells using Image-Pro Plus version 7.0 (Media Cybernetics, Inc., Rockville, MD, USA). In total, $\sim 1,000$ cells were counted for each tumor specimen. In order to evaluate the expression of Prx1, ASK1, p38 and phosphor-ASK1, the stained cells from three to five representative microscope fields were counted for each specimen (magnification, $\mathrm{x} 200$ ) and the mean optical density (MOD) was calculated for each mouse tongue tissue using Image-Pro Plus version 7.0 software as follows: $\mathrm{MOD}=$ integrated option density / area.

Reverse transcription-quantitative polymerase chain reaction (RT-qPCR). Total RNA was extracted from mouse tongue tissues using TRIzol Reagent (Invitrogen ${ }^{\mathrm{TM}}$; Thermo Fisher Scientific, Inc., Waltham, MA, USA), according to the manufacturer's protocol. cDNA was synthesized by reverse transcribing $2 \mu \mathrm{g}$ RNA with the High-Capacity cDNA Reverse Transcription kit (Applied Biosystems ${ }^{\circledR}$; Thermo Fisher Scientific, Inc.). In total, $1 \mu 1$ aliquots of cDNA were used as the templates for qPCR. Sequences for all target gene primers were synthesized by Sangon Biotech (Shanghai, China) as follows: Prx1, forward: 5'-AATGCAAAAATTGGGTATCCTGC-3' and reverse 5'-CGTGGGACACACAAAAGTAAAGT-3'; ASK1, forward: 5'-AAGTCCCAACCCATAGAAATTCCT-3' and reverse 5'-AGCCAGTCGGTAAGTTCAGAATCTT-3'; p38, forward 5'-GAGCTGAAGATTCTGGATTTTGG-3' and reverse 5'-TAGCCACGTAGCCGGTCATT-3'; glyceraldehyde 3-phosphate dehydrogenase (GAPDH), forward 5'-AGGTCG GTGTGAACGGATTTG-3' and reverse 5'-TGTAGACCA TGAGTTGAGGTCA-3'. The cycling conditions for RT-PCR were as follows: $25^{\circ} \mathrm{C}$ for $10 \mathrm{~min}, 37^{\circ} \mathrm{C}$ for $120 \mathrm{~min}$ and $85^{\circ} \mathrm{C}$ for $5 \mathrm{~min}$. The UltraSYBR Mixture (With ROX) (ComWin Biotech Co., Ltd., Beijing, China) was used for qPCR, and the cycling conditions were as follows: $95^{\circ} \mathrm{C}$ for $10 \mathrm{~min}, 95^{\circ} \mathrm{C}$ for $15 \mathrm{sec}$ and $60^{\circ} \mathrm{C}$ for $15 \mathrm{sec}$ for 40 cycles. For data analysis, the $2^{-\Delta \Delta \mathrm{Cq}}$ method (25) was used for the normalization of the genes of interest against GAPDH. The experiments were conducted three times.

Statistical analysis. Statistically significant differences were analyzed by $\chi^{2}$, two-tailed Student's t-test and Kruskal-Wallis one-way analysis of variance test. Bonferroni was used as a post-hoc test. SPSS version 17.0 software (SPSS, Inc., Chicago, IL, USA) was used for analysis. $\mathrm{P}<0.05$ was considered to indicate a statistically significant difference. $\mathrm{P}<0.017$ was considered to indicate a statistically significant difference in the Bonferroni test.

\section{Results}

Tongue precancerous lesion model established in Prxl knockout mice. 4NQO was used to induce the development of tongue precancerous lesions in Prx1 knockout and wild-type mice. No tongue precancerous lesions were observed in the control mice at the end of the 16th week, while in Prx1 knockout and wild-type mice treated with $4 \mathrm{NQO}$ or $4 \mathrm{NQO}+\mathrm{H}_{2} \mathrm{O}_{2}$ the tongues of the mice exhibited white, thick, rough and visible white patches as well as surface toughness. Histological observation revealed epithelial dysplasia with varying degrees and OSCC on the tongues, indicating that the model of tongue

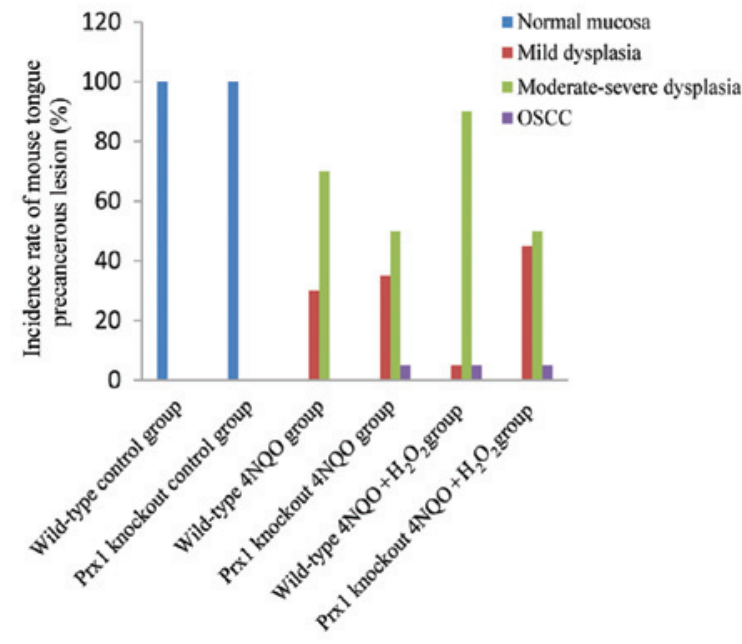

Figure 1. Incidence and type of mouse tongue precancerous lesions in six experimental mouse models used in the present study. Control groups, $n=10$; other groups, $\mathrm{n}=20$. Prx1, peroxiredoxin 1; 4NQO, 4-nitroquinoline-1-oxide; OSCC, oral squamous cell carcinoma.

precancerous lesions in Prx1 knockout mice was successfully established. There was a significant decrease in the degree of moderate or severe epithelial dysplasia $(\mathrm{P}=0.016)$, and mild epithelial dysplasia was clearly elevated $(\mathrm{P}=0.011)$, in Prx1 knockout mice treated with $4 \mathrm{NQO}+\mathrm{H}_{2} \mathrm{O}_{2}$ compared with wild-type mice treated with $4 \mathrm{NQO}+\mathrm{H}_{2} \mathrm{O}_{2}$ (Fig. 1; Table I). The application of $3 \% \mathrm{H}_{2} \mathrm{O}_{2}$ alone ( 3 times/week) did not induce epithelial dysplasia of tongue mucosa over 16 weeks (data not shown). These results indicated that $\operatorname{Prx} 1$ and $\mathrm{H}_{2} \mathrm{O}_{2}$ play a coordination role in promoting the progression of tongue precancerous lesions.

Prxl is over-expressed in tongue precancerous lesions. The expression of Prx1 was analyzed by RT-qPCR and immunohistochemical staining. The mRNA expression of Prx1 was increased in the wild-type 4NQO group compared with the wild-type control group $(\mathrm{P}=0.046)$. The mRNA expression level of Prx1 was also increased in the wild-type 4NQO $+\mathrm{H}_{2} \mathrm{O}_{2}$ group compared with the wild-type control group $(\mathrm{P}=0.009)$. There was no statistically significant difference in mRNA expression between the wild-type $4 \mathrm{NQO}$ and $4 \mathrm{NQO}+\mathrm{H}_{2} \mathrm{O}_{2}$ groups (Fig. 2A). The protein expression levels of Prx1 were increased in the $4 \mathrm{NQO}$ and $4 \mathrm{NQO}+\mathrm{H}_{2} \mathrm{O}_{2}$ groups compared with mice from the wild-type control group $(\mathrm{P}=0.035$ and $\mathrm{P}=0.024$, respectively). The expression of Prx 1 in the $4 \mathrm{NQO}+\mathrm{H}_{2} \mathrm{O}_{2}$ group was increased compared with the 4NQO group, but this was not statistically significant $(\mathrm{P}=0.847$; Fig. 2B). These results indicate that Prx1 may be important in promoting cell proliferation in oral precancerous lesions.

Prxl knockout increases cell apoptosis in tongue precancerous lesions. The apoptotic rate in the wild-type 4NQO group was elevated compared with the wild-type control group $(\mathrm{P}<0.001)$. The apoptotic rate in the wild-type 4NQO $+\mathrm{H}_{2} \mathrm{O}_{2}$ group was decreased compared with the 4NQO group $(\mathrm{P}=0.004)$. An increased apoptotic rate in the Prx1 knockout $4 \mathrm{NQO}$ and Prx1 knockout 4NQO $+\mathrm{H}_{2} \mathrm{O}_{2}$ groups was observed compared with the wild-type 4NQO $(\mathrm{P}=0.009)$ and wild-type 
Table I. Incidence and type of mouse tongue precancerous lesions in six experimental mouse models.

\begin{tabular}{|c|c|c|c|c|c|}
\hline Group & $\mathrm{n}$ & $\begin{array}{c}\text { Normal } \\
\text { mucosal, n }(\%)\end{array}$ & $\begin{array}{c}\text { Mild } \\
\text { dysplasia, n (\%) }\end{array}$ & $\begin{array}{l}\text { Moderate-severe } \\
\text { dysplasia, n (\%) }\end{array}$ & OSCC, n (\%) \\
\hline Total & 100 & & & & \\
\hline Wild-type control & 10 & $10(100)$ & $0(0)$ & $0(0)$ & $0(0)$ \\
\hline Prx1 knockout control & 10 & $10(100)$ & $0(0)$ & $0(0)$ & $0(0)$ \\
\hline Wild-type 4NQO & 20 & $0(0)$ & $6(30)$ & $14(70)$ & $0(0)$ \\
\hline Prx1 knockout 4NQO & 20 & $0(0)$ & $7(35)$ & $12(50)$ & $1(5)$ \\
\hline Wild-type 4NQO + $\mathrm{H}_{2} \mathrm{O}_{2}$ & 20 & $0(0)$ & $1(5)$ & $18(90)$ & $1(5)$ \\
\hline Prx1 knockout 4NQO $+\mathrm{H}_{2} \mathrm{O}_{2}$ & 20 & $0(0)$ & $9(45)^{\mathrm{a}}$ & $10(50)^{\mathrm{a}}$ & $1(5)$ \\
\hline
\end{tabular}

aP $<0.05$ vs. wild-type $4 \mathrm{NQO}+\mathrm{H}_{2} \mathrm{O}_{2}$ group. OSCC, oral squamous cell carcinoma; Prx1, peroxiredoxin 1; 4NQO, 4-nitroquinoline-1-oxide.

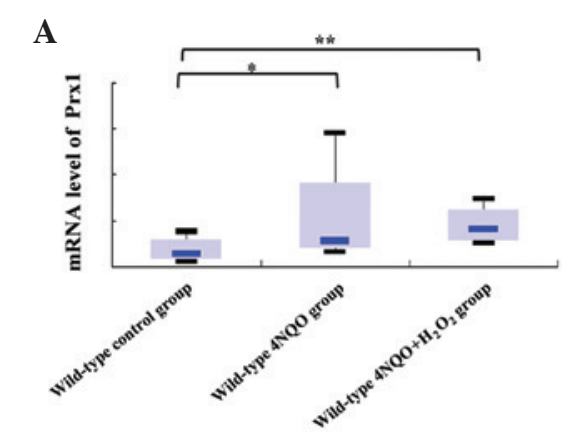

B a
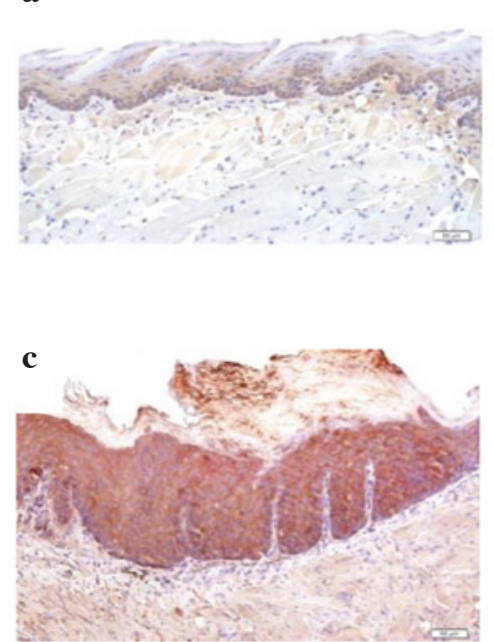
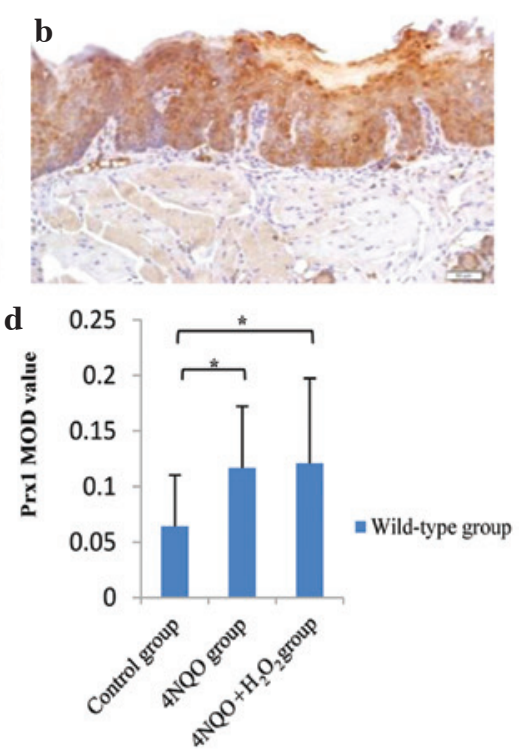

Figure 2. Prx1 is over-expressed in tongue precancerous lesions. (A) mRNA level of Prx1 in wild-type mice determined by reverse transcription polymerase chain reaction. (B) Positive expression of Prx1 in mouse tongue premalignant lesions in the (a) wild-type control group, (b) wild-type 4NQO group and (c) wild-type 4NQO $+\mathrm{H}_{2} \mathrm{O}_{2}$ group (magnification, x200). (d) Prx1 MOD value. ${ }^{*} 0.01<\mathrm{P}<0.05$; ${ }^{* *} 0.001<\mathrm{P}<0.01$. Prx1, peroxiredoxin 1; 4NQO, 4-nitroquinoline-1-oxide; MOD, mean optical density.

$4 \mathrm{NQO}+\mathrm{H}_{2} \mathrm{O}_{2}$ groups $(\mathrm{P}=0.024)$, respectively. These results indicate that Prx1 inhibits apoptosis in tongue precancerous lesions (Fig. 3A and B).

Prxl knockout results in the downregulation of ASK1. In order to evaluate the effect of Prx1 on the activation of ASK1 in tongue precancerous lesions, the expression of total ASK1 and phosphor-ASK1 was observed in Prx1 knockout and wild-type mice. The present results demonstrated that the mRNA expression level of ASK1 was increased in wild-type 4NQO and wild-type $4 \mathrm{NQO}+\mathrm{H}_{2} \mathrm{O}_{2}$ groups compared with the wild-type control group $(\mathrm{P}=0.001$ and $\mathrm{P}=0.002$, respectively; Fig. 4A). A statistically significant difference in the mRNA expression level of ASK1 between wild-type 4NQO and $4 \mathrm{NQO}+\mathrm{H}_{2} \mathrm{O}_{2}$ groups was observed. The mRNA expression level of ASK1 was increased in Prx1 knockout control group compared with wild-type control group $(\mathrm{P}=0.003$; Fig. 4Ba). The mRNA expression level of ASK1 in Prx1 knockout 4NQO and Prx1 knockout 4NQO $+\mathrm{H}_{2} \mathrm{O}_{2}$ groups was increased compared with the wild-type group, although this was not statistically significant $(\mathrm{P}=0.704$ and $\mathrm{P}=0.24$, respectively; Fig. $4 \mathrm{Bb}$ and c).

Immunohistochemical analysis revealed that there was no statistically significant difference in protein expression of ASK1 between any groups (Fig. 4C). Compared with the wild-type 4NQO group, the expression of phosphor-ASK1 was decreased in the Prx1 knockout 4NQO group $(\mathrm{P}=0.022)$. A similar expression pattern was observed in wild-type and Prx1 knockout 4NQO $+\mathrm{H}_{2} \mathrm{O}_{2}$ groups $(\mathrm{P}=0.001)$. There was no significant difference in the phosphorylation of ASK1 in the wild-type $4 \mathrm{NQO}$ and wild-type $4 \mathrm{NQO}+\mathrm{H}_{2} \mathrm{O}_{2}$ groups compared with the wild-type control group $(\mathrm{P}=0.481$ and $\mathrm{P}=0.104)$, suggesting that phosphor-ASK1 has a positive association with Prx1 expression (Fig. 4D).

Prxl knockout suppresses the expression of p38. In order to evaluate the effect of Prx1 on the activation of p38 MAPK in tongue precancerous lesions, the expression of total p38 and 
$\mathbf{A}_{\mathbf{a}}$
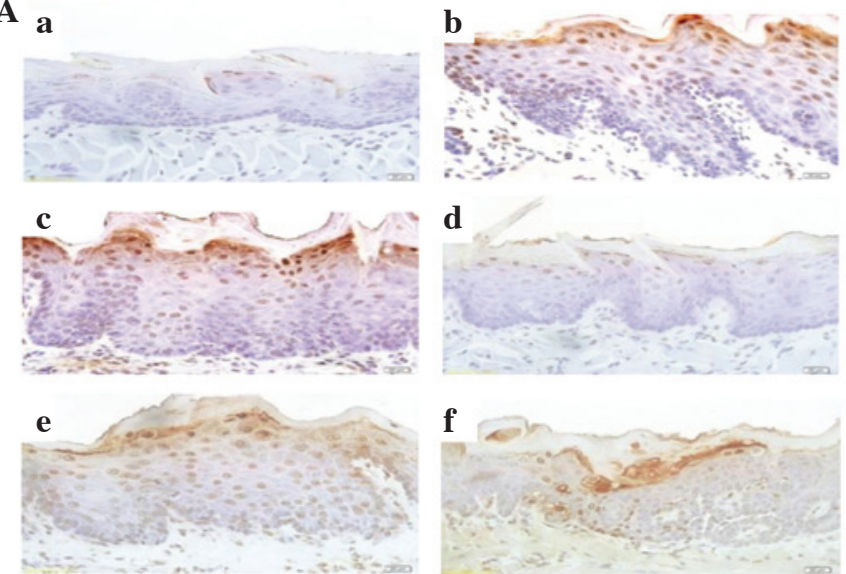

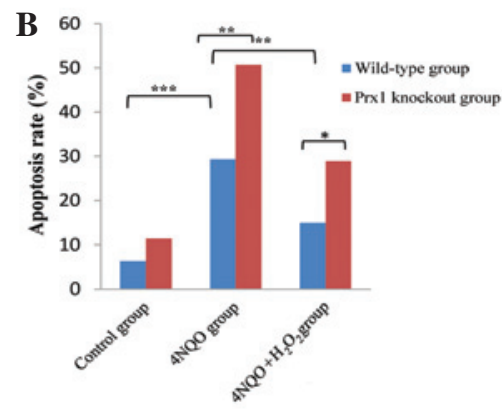

Figure 3. Prx1 knockout increases cell apoptosis in tongue precancerous lesions. (A) Terminal deoxynucleotidyl transferase dUTP nick-end labeling assay in (a) wild-type control group, (b) wild-type 4NQO group, (c) wild-type 4NQO $+\mathrm{H}_{2} \mathrm{O}_{2}$ group, (d) Prx1 knockout control group, (e) Prx1 knockout 4NQO group and (f) Prx1 knockout 4NQO $+\mathrm{H}_{2} \mathrm{O}_{2}$ group (magnification, $\mathrm{x} 400$ ). (B) Prx1 negatively regulated the apoptotic rate of cells in mouse tongue premalignant lesions. ${ }^{*} 0.01<\mathrm{P}<0.05 ;{ }^{* *} 0.000<\mathrm{P}<0.01 ;{ }^{* * * *} \mathrm{P}=0.000$. Prx1, peroxiredoxin 1; 4NQO, 4-nitroquinoline-1-oxide.
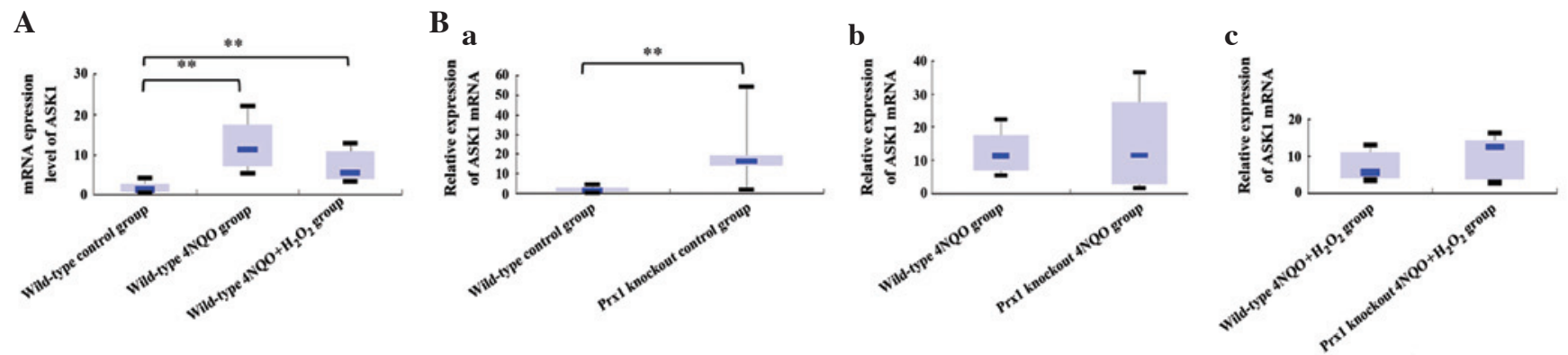

C

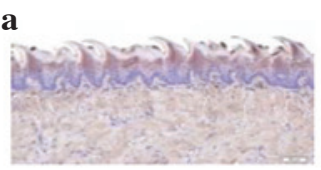

c
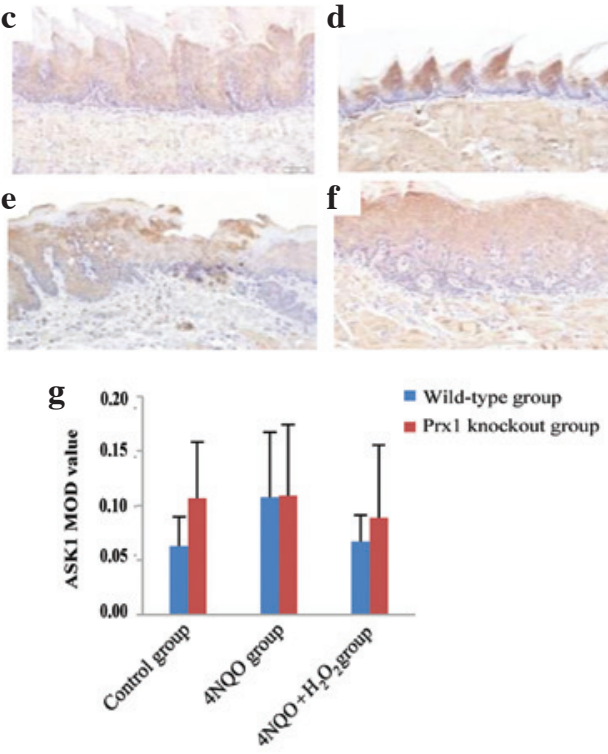

D b

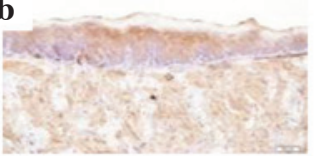

d
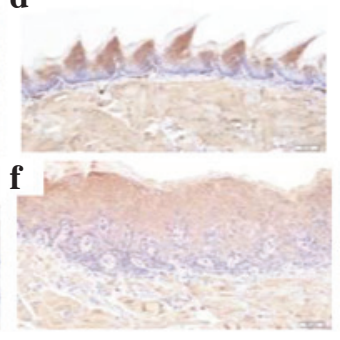

a

e b

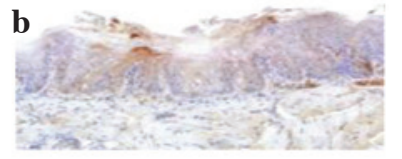

d
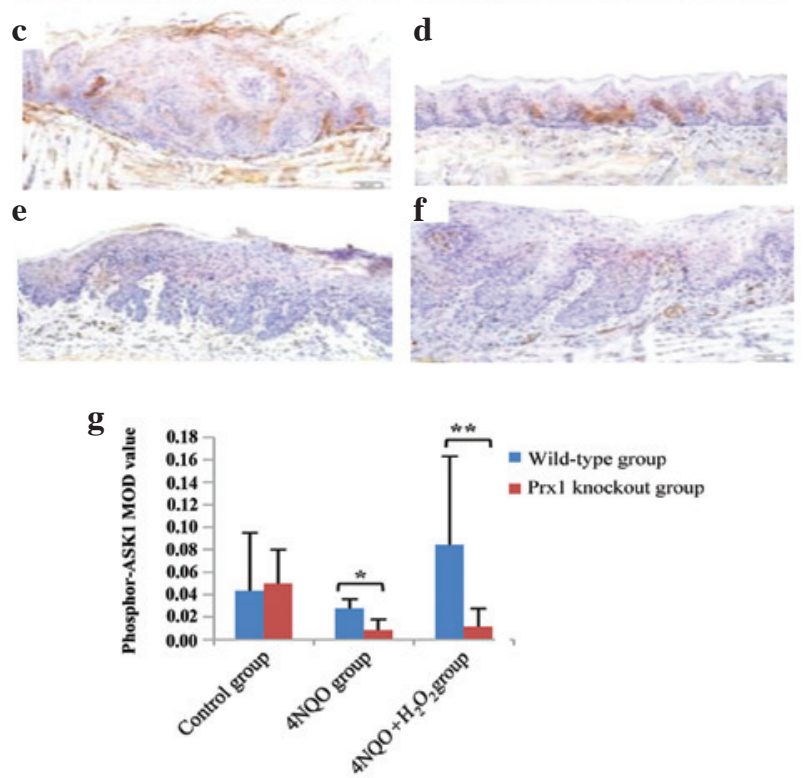

Figure 4. Prx1 knockout leads to a downregulation of ASK1. (A) mRNA expression level of ASK1 was elevated in mouse tongue premalignant lesions, as determined by RT-qPCR. (B) RT-qPCR determination of the relative expression of ASK1 mRNA in Prx1 knockout mice (a) control group, (b) 4NQO group and (c) 4NQO $+\mathrm{H}_{2} \mathrm{O}_{2}$ group. (C) Prx1 had no clear association with ASK1 in mouse tongue premalignant lesions in the (a) wild-type control group, (b) wild-type 4NQO group, (c) wild-type 4NQO $+\mathrm{H}_{2} \mathrm{O}_{2}$ group, (d) Prx1 knockout control group, (e) Prx1 knockout 4NQO group and (f) Prx1 knockout 4NQO + $\mathrm{H}_{2} \mathrm{O}_{2}$ group (magnification, x200). (g) ASK1 MOD value. (D) Prx1 positively regulated the activation of phosphor-ASK1 in mouse tongue premalignant lesions in the (a) wild-type control group, (b) wild-type 4NQO group, (c) wild-type 4NQO $+\mathrm{H}_{2} \mathrm{O}_{2}$ group, (d) Prx1 knockout control group, (e) Prx1 knockout 4NQO group and (f) Prx1 knockout 4NQO $+\mathrm{H}_{2} \mathrm{O}_{2}$ group (magnification, x200). (g) Phosphor-ASK1 MOD value. ${ }^{*} 0.01<\mathrm{P}<0.05$; ${ }^{* *} 0.000<\mathrm{P}<0.01$. Prx1, peroxiredoxin 1; 4NQO, 4-nitroquinoline-1-oxide; ASK-1, apoptosis signal-regulating kinase 1; MOD, mean optical density; RT-qPCR, reverse transcription-quantitative polymerase chain reaction. 


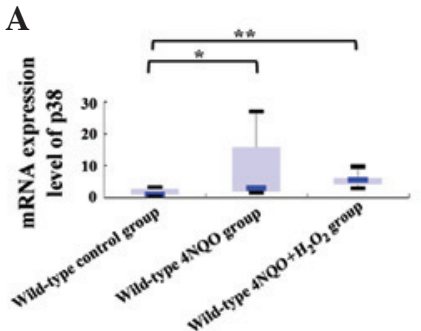

C

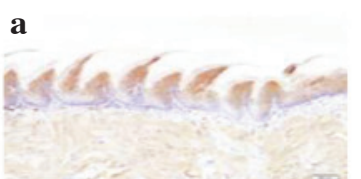

c

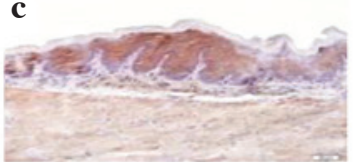

e

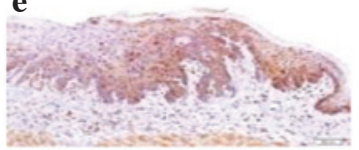

B $\mathbf{a}$

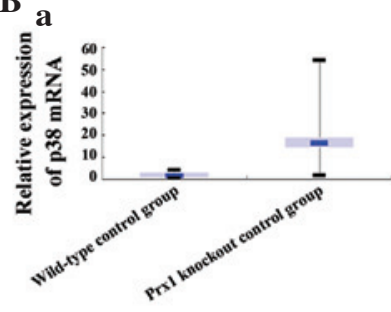

D

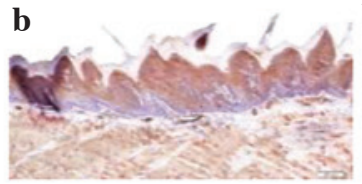

d
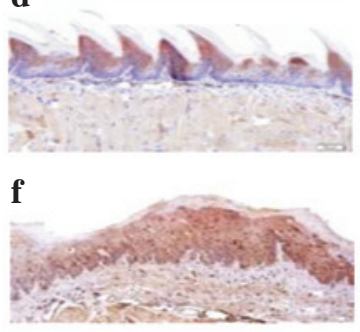

= Wild-type group

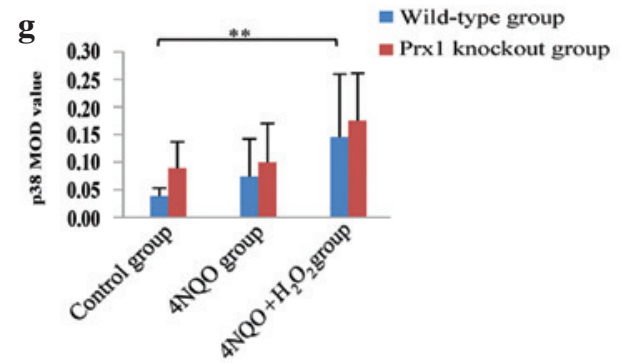

b
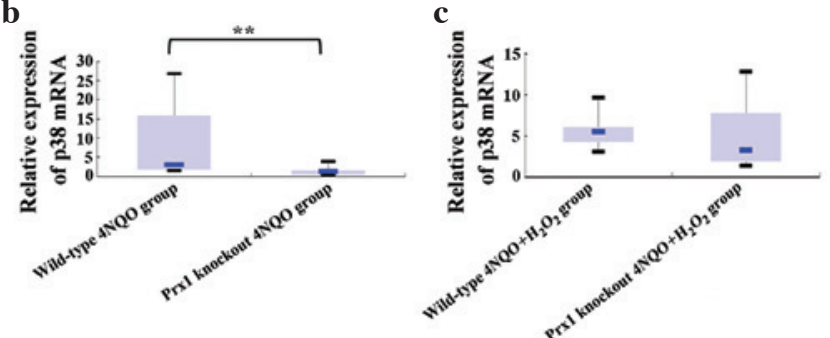
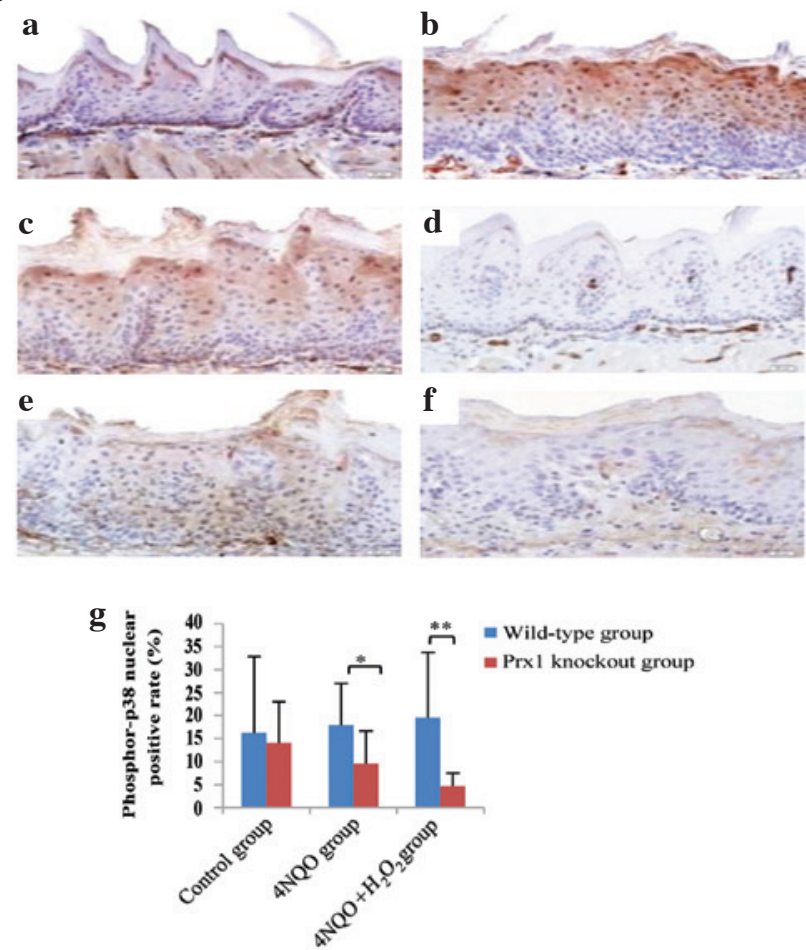

Figure 5. Prx1 knockout suppresses the expression of p38. (A) mRNA expression level of p38 was elevated in mouse tongue premalignant lesions, as determined by RT-qPCR. (B) RT-qPCR determined the relative expression level of p38 mRNA in Prx1 knockout mice (a) control group, (b) 4NQO group and (c) $4 \mathrm{NQO}+\mathrm{H}_{2} \mathrm{O}_{2}$ group. (C) Prx1 positively regulated the activation of p38 in mouse tongue premalignant lesions in the (a) wild-type control group, (b) wild-type 4NQO group, (c) wild-type 4NQO $+\mathrm{H}_{2} \mathrm{O}_{2}$ group, (d) Prx1 knockout control group, (e) Prx1 knockout 4NQO group and (f) Prx1 knockout 4NQO $+\mathrm{H}_{2} \mathrm{O}_{2}$ group (magnification, x200). (g) p38 MOD value. (D) Prx1 positively regulated the activation of phosphor-p38 in mouse tongue premalignant lesions in the (a) wild-type control group, (b) wild-type 4NQO group, (c) wild-type 4NQO $+\mathrm{H}_{2} \mathrm{O}_{2}$ group, (d) Prx1 knockout control group, (e) Prx1 knockout 4NQO group and (f) Prx 1 knockout $4 \mathrm{NQO}+\mathrm{H}_{2} \mathrm{O}_{2}$ group (magnification, $\mathrm{x} 400$ ). (g) Nuclear positive rate of phosphor-p38. ${ }^{*} 0.01<\mathrm{P}<0.05$; ${ }^{* *} 0.000<\mathrm{P}<0.01$. Prx1, peroxiredoxin 1; 4NQO, 4-nitroquinoline-1-oxide; MOD, mean optical density; RT-qPCR, reverse transcription-quantitative polymerase chain reaction.

phosphor-p38 was detected in Prx1 knockout and wild-type mice. The mRNA expression level of $\mathrm{p} 38$ was increased in the wild-type $4 \mathrm{NQO}$ and $4 \mathrm{NQO}+\mathrm{H}_{2} \mathrm{O}_{2}$ groups compared with the wild-type control group ( $\mathrm{P}=0.021$ and $\mathrm{P}=0.001$, respectively). The difference in mRNA expression levels of p38 between wild-type 4NQO and 4NQO $+\mathrm{H}_{2} \mathrm{O}_{2}$ groups was not statistically significant $(\mathrm{P}=0.401$; Fig. 5A). The mRNA expression level of p38 was decreased in the Prx1 knockout 4NQO group compared with the wild-type $4 \mathrm{NQO}$ group $(\mathrm{P}=0.006)$. The mRNA expression of p38 was decreased in the Prx 1 knockout $4 \mathrm{NQO}+\mathrm{H}_{2} \mathrm{O}_{2}$ group, although no statistically significant difference was observed with the wild-type $4 \mathrm{NQO}+\mathrm{H}_{2} \mathrm{O}_{2}$ group ( $\mathrm{P}=0.649$; Fig. 5B).

The protein expression of $\mathrm{p} 38$ was clearly increased in the wild-type $4 \mathrm{NQO}+\mathrm{H}_{2} \mathrm{O}_{2}$ group compared with the wild-type control group ( $\mathrm{P}=0.002$; Fig. 5C). The level of phosphor-p38 was decreased in the Prx1 knockout 4NQO group compared with the wild-type $4 \mathrm{NQO}$ group $(\mathrm{P}=0.022)$. The same expression pattern was observed in Prx1 knockout and wild-type 4NQO $+\mathrm{H}_{2} \mathrm{O}_{2}$ groups $(\mathrm{P}=0.001)$. The expression level of phosphor-p38 was not significantly different in the wild-type 4NQO and 4NQO $+\mathrm{H}_{2} \mathrm{O}_{2}$ groups compared with the wild-type control groups $(\mathrm{P}=0.606$ and $\mathrm{P}=0.333$, respectively), indicating that phosphor-p38 had a clear positive association with the expression of Prx1 (Fig. 5D).

\section{Discussion}

OLK is the most common oral precancerous lesion, which may undergo a carcinomatous change to OSCC (26). At present, little is known concerning the pathogenesis of OLK. Previous studies have demonstrated that cell apoptosis is suppressed by Prx1 via the ASK1-mediated signaling pathway in human embryonic kidney 293 and cervical cancer HeLa cells (23). In a previous study by the present authors, an increased level of apoptosis was observed in OLK tissues, and Prx1 knockdown significantly enhanced the level of apoptosis in dysplastic oral keratinocyte 
cells (data not shown). However, even though there are numerous in vitro studies concerning Prx1 and cell apoptosis, there are few in vivo studies. The present study has for the first time, to the best of our knowledge, designed carcinogenic experiments in vivo to observe the effect of Prx1 on cell apoptosis during the initiation and progression to malignancy of oral mucosa. In order to confirm the role of Prx1 in oral precancerous lesions in vivo, the present study established tongue precancerous lesion mouse models in Prx 1 knockout mice and investigated whether Prx1 suppresses apoptosis induced by oxidative stress. The present study elucidated the possible molecular mechanism during the pathogenesis and development of oral precancerous lesions.

In eukaryotic cells, four MAPK signal transduction pathways, including extracellular signal-regulated kinase (ERK) 1/2,JNK, p38 and ERK5, have been identified. ERK1/2, JNK and p38 pathways are typical MAPK signal transduction pathways. Furthermore, JNK and p38 signaling pathways are associated with cell apoptosis (27-29). ASK1 is known as a proapoptotic, stress-activated signaling molecule, and is an ubiquitously expressed serine-theronine protein kinase that functions as a MAPK kinase to activate JNK and p38 MAPK signaling cascades (30). Prx1 is the most abundant and ubiquitously distributed member of the mammalian Prx family. It has been implicated in regulating cell proliferation, differentiation and apoptosis $(31,32)$. ASK1 interacts with Prx1 in the presence of $\mathrm{H}_{2} \mathrm{O}_{2}$-induced stress and is negatively regulated by Prx1 (23). Nakagawa et al (33) have demonstrated that the activation of JNK and p38 is attenuated and hepatocarcinogenesis is increased in ASK1-deficient mice. Yan et al (34) have identified that ASK1 activated by arsenic trioxide in leukemic cells may play an antiapoptotic role, and Park et al (35) have demonstrated that Bacillus anthracis induces the apoptosis of activated macrophages by inhibiting the p38 MAPK pathway.

In the present study, the apoptotic rate of cells increased and the expression of phosphor-ASK1 and phosphor-p38 was downregulated in tongue precancerous lesions of Prx 1 knockout mice. These results demonstrate that apoptosis suppression by Prx1 may be associated with the phosphorylation of ASK1 and p38, and that Prx1 has a positive regulatory role in the phosphorylation of ASK1 and p38. In addition, the present study also detected the transcription level of Prx1, ASK1 and p38 compared with that in normal epithelium, and the expression of Prx1, ASK1 and p38 was clearly increased in precancerous lesions compared with normal epithelium. When Prx1 was knocked-down, the ASK1 transcription level was significantly increased in the control group, indicating that Prx1 clearly inhibits the transcription of ASK1 in normal mucosa. By contrast, a knockdown of Prx1 resulted in a significant downregulation of p38 at a transcriptional level in the precancerous lesions, suggesting that Prx 1 also positively regulates p38 in precancerous lesions. Overall, Prx1 suppresses oxidative stress-induced apoptosis in tongue precancerous lesions by positively regulating ASK 1 and p38 expression at a molecular level.

In the present study, in the Prx1 knockout 4NQO $+\mathrm{H}_{2} \mathrm{O}_{2}$ mice, the degree of moderate to severe epithelial dysplasia was significantly reduced and mild epithelial dysplasia was clearly elevated compared with wild-type 4NQO $+\mathrm{H}_{2} \mathrm{O}_{2}$ mice This suggests that Prx1 enhances cell proliferation during the pathogenesis of oral precancerous lesions. Therefore, when oral precancerous lesions are affected by oxidative stress, Prx1 is important in inhibiting oxidative damage and apoptosis of cells, and promotes the progression of tongue precancerous lesions. Lee et al (36) have also demonstrated that Prx1 knockout results in the decrease of cell proliferation, and Prx 1 is associated with tumor size, micro-vassal invasion and Edmonson tumor grade (37). In addition, microRNA-510 directly binds to the 3'-untranslated region of Prx1 and blocks its protein expression, leading to a suppression in the migration of human breast cancer cells (38).

In the present study, the application of $\mathrm{H}_{2} \mathrm{O}_{2}$ alone as an oxidative stressor had no obvious effect on lesion development. However, more severe lesions were observed in mice from the wild-type $4 \mathrm{NQO}+\mathrm{H}_{2} \mathrm{O}_{2}$ group compared with mice from the wild-type $4 \mathrm{NQO}$ group, indicating that $\mathrm{H}_{2} \mathrm{O}_{2}$ application coupled with $4 \mathrm{NQO}$ has a positive effect on promoting the development and progression of lesions. $\mathrm{H}_{2} \mathrm{O}_{2}$ is known as the most common member of ROS and induces apoptosis in various types of malignances $(39,40)$. However, in the present study, compared with 4NQO-induced tongue precancerous lesions, cell apoptosis was moderately reduced in mice from the $4 \mathrm{NQO}+\mathrm{H}_{2} \mathrm{O}_{2}$ group. A similar pattern was observed in Prx1 knockout mice. Previous studies have revealed that 4NQO treatment leads to the formation of $\mathrm{H}_{2} \mathrm{O}_{2}$ superoxide and hydroxyl radicals, thus resulting in the production of a substantial amount of 8-OHdG in DNA and oxidative damage in normal human fibroblasts (41). Tang et al (42) have demonstrated that $\mathrm{H}_{2} \mathrm{O}_{2}$ preconditioning at low concentrations may protect rat pheochromocytoma PC12 cells from apoptosis induced by $\mathrm{H}_{2} \mathrm{O}_{2}$. In addition, oxidant preconditioning protects human proximal tubular cells against lethal oxidant injury (43). In the present study, $3 \% \mathrm{H}_{2} \mathrm{O}_{2}$ was applied to mouse tongue mucosa three times a week during the development of 4NQO-induced mouse tongue precancerous lesions for 16 weeks. The $3 \% \mathrm{H}_{2} \mathrm{O}_{2}$ was revealed to be a mild stimulus compared with $50 \mu \mathrm{g} / \mathrm{ml}$ 4NQO. The $3 \% \mathrm{H}_{2} \mathrm{O}_{2}$ treatment may alleviate apoptosis induced by subsequent 4NQO exposure in tongue mucosa epithelia of the mice. These data indicate that $\mathrm{H}_{2} \mathrm{O}_{2}$ at a low concentration may inhibit apoptosis. A previous study also revealed that $\mathrm{H}_{2} \mathrm{O}_{2}$ at a low concentration promotes cell proliferation (44). A low dose of $\mathrm{H}_{2} \mathrm{O}_{2}$ was able to reverse DHM-induced cell apoptosis of human hepatocellular carcinoma (44). This may indicate that the balance between ROS production and various antioxidants is vitally important for cancer cell growth.

The present carcinogenic in vivo experiments were used to observe the effect of Prx1 on cell apoptosis during the development and progression to malignancy of mouse tongue mucosa. The present study concludes that Prx1 may suppress oxidative stress-induced apoptosis via the ASK1/p38 signaling pathway in mouse tongue precancerous lesions, and $\mathrm{H}_{2} \mathrm{O}_{2}$ and 4NQO play a coordination role in promoting the progression of tongue mucosa precancerous lesions. In addition, $\mathrm{H}_{2} \mathrm{O}_{2}$ at a low concentration level may inhibit apoptosis. The present findings provide novel insights into Prx1 function and the mechanisms of OLK pathogenesis.

\section{Acknowledgements}

The present study was funded by the National Natural Science Foundation of China, Beijing, China (grant nos. 81070836 and 
81470752) and Beijing Natural Science Foundation of China, Beijing, China (grant no. 7152066).

\section{References}

1. van der Waal I: Oral potentially malignant disorders: Is malignant transformation predictable and preventable? Med Oral Patol Oral Cir Bucal 19: e386-e390, 2014.

2. Amaqasa T, Yamashiro M and Uzawa N: Oral premalignant lesions: From a clinical perspective. Int J Clin Oncol 16: 5-14, 2011

3. Wamakulasuriya S: Global epidemiology of oral and oropharyngeal cancer. Oral Oncol 45: 309-316, 2009.

4. Van der Waal I, Schepman KP, Vander Meij EH and Smeele LE: Oral leukoplakia: A Clinicopathological review. Oral Oncol 33: 291-301, 1997.

5. Van der Waal I and Axell T: Oral leukoplakia: A proposal for uniform reporting. Oral Oncol 38: 521-526, 2002.

6. Banoczy J, Gintner Z and Dombi C: Tobacco use and oral leukoplakia. J Dent Educ 65: 322-327, 2001.

7. Reichart PA: Identification of risk groups for oral precancer and cancer and preventive measures. Clin Oral Investing 5: 207-213, 2001.

8. Zhang XL and Reichart PA: A review of betel quid chewing, oral cancer and precancer in mainland China. Oral Oncology 43: 424-430, 2007.

9. Chen CL, Chi CW and Liu TY: Hydroxyl radical formation and oxidative DNA damage induced by area quid in vivo. J Toxicol Environ Health A 65: 327-336, 2002.

10. Christen AG, Swanson BZ, Glover ED and Henderson AH: Smokeless tobacco: The folklore and social history of snuffing, sneezing, dipping, andchewing.JAmDentAssoc 105:821-829,1982.

11. Oda D, Nguyen MP, Royack GA and Tong DC: $\mathrm{H}_{2} \mathrm{O}_{2}$ oxidative damage incultured oral epithelial cells: The effect of short-term vitamin C exposure. Anticancer Res 21: 2719-2724, 2001.

12. Wu HJ, Chi CW and Liu TY: Effects of PH on nicotine-induced DNA damage and oxidative stress. J Toxicol Environ Health A 68: 1511-1523, 2005.

13. Bahar G, Feinmesser R, Shpitzer T, Popovtzer A and Nagler RM: Salivary analysis in oral cancer patients: DNA and protein oxidation, reactive nitrogen species, and antioxidant profile. Cancer 109: 54-59, 2007.

14. Circu ML and Aw TY: Reactive oxygen species, cellular redox systems, and apoptosis. Free Radic Biol Med 48: 749-762, 2010.

15. Rhee SG and Woo HA: Multiple functions of peroxiredoxins: Peroxidases, sensors and regulatoers of the intracellular messenger $\mathrm{H}_{2} \mathrm{O}_{2}$ and protein chaperones. Antioxid Redox Signal 15: 781-794, 2011 .

16. Kang SW, Rhee SG, Chang TS, Jeong W and Choi MH: 2-Cys perosiredoxin function is intracellular signal transduction: Therapeutic implications. Trends Mol Med 11: 571-578, 2005.

17. Yanagawa T, Iwasa S, Ishii T, Tabuchi K, Yusa H, Onizawa K, Omura K, Harada H, Suzuki H and Yoshida H: Peroxiredoxin 1 expression in oral cancer: A potential new tumor marker. Cancer Lett 156: 27-35, 2000.

18. Yanagawa T, Omura K, Harada H, Ishii T, Uwayama J, Nakaso K, Iwasa S, Koyama Y, Onizawa K, Yusa H and Yoshida H: Peroxiredoxin 1 expression in tongue squamous cell carcinomas as involved in tumor recurrence. Int J Oral Maxillofac Surg 34: 915-920, 2005.

19. Ge Li-hua, Hou Min, Yang Jing, Chen Tong and Tang Xiao-fei: Prx1 overexpression in human oral leukoplakia. Beijing Kou Qiang Yi Xue Za Zhi 20: 135-137, 2012 (In Chinese).

20. Nishitoh H, Saitoh M, Mochida Y, Takeda K, Nakano H, Rothe M, Miyazono K and Ichijo H: ASK1 is essential for JNK/SAPK activation by TRAF2. Mol Cell 2: 389-395, 1998.

21. Saitoh M, Nishitoh H, Fujii M, Takeda K, Tobiume K, Sawada Y, Kawabata M, Miyazono K and Ichijo H: Mammalian thioredoxin is a direct inhibitor of apoptosis signal-regulating kinase (ASK) 1. EMBO J 17: 2596-2606, 1998.

22. Takeda K, Matsuzawa A, Nishitoh $\mathrm{H}$ and Ichijo $\mathrm{H}$ : Roles of MAPKKK ASK1 in stress-induce cell death. Cell Struct Funct 28: 23-29, 2003.

23. Kim SY, Kim TJ and Lee KY: A novel function of peroxiredoxin 1 (Prx-1) in apoptosis signal-regulating kinase 1 (ASK1)-mediated signaling pathway. FEBS Lett 582: 1913-1918, 2008.

24. Zhang Min, Liang Hong, Quan Xiong-Zhi, Miao Cong-cong and Tang Xiao-Fei: Establishment of Prx 1 gene knockout mice. Beijing Kou Qiang Yi Xue Za Zhi 20: 246-248, 2012 (In Chinese).
25. Livak KJ and Schmittgen TD: Analysis of relative gene expression data using real-time quantitative PCR and the 2(-Delta Delta C(T)) Method. Methods 25: 402-408, 2001.

26. Kramer IR, Lucas RB, Pindborg JJ and Sobin LH: Definition of leukoplakia and related lesions: An aid to studies on oral precancer. Oral Surg Oral Med Oral Pathol 46: 518-539, 1978.

27. Chen CL, Lin DF, Chang WT, Huang WC, Teng CF and Lin YS Ceramide induces p38 MAPK and JNK activation through a mechanism involving a thioredoxin-interacting protein-mediated pathway. Blood 111: 4365-4374, 2008

28. Park GB, Kim YS, Lee HK, Song H, Cho DH, Lee WJ and Hur DY: Endoplasmic reticulum stress-mediated apoptosis of EBV-transformed B cells by cross-linking of CD70 is dependent upon generation of reactive oxygen species and activation of $\mathrm{p} 38$ MAPK and JNK pathway. J Immunol 185: 7274-7284, 2010.

29. Zhang J, Tang J, Cao B, Zhang Z, Li J, Schimmer AD, He S and Mao X: The natural pesticide dihydrorotenone induces human plasma cell apoptosis by triggering endoplasmic reticulum stress and activating p38 signaling pathway. PLoS One 8: e69911, 2013.

30. Ichijo H, Nishida E, Irie K, ten Dijke P, Saitoh M, Moriquchi T, Takaqi M, Matsumoto K, Miyazono K and Gotoh Y: Induction of apoptosis by ASK1, a mammalian MAPKKK that activates SAPK/JMK and p38 signaling pathway. Science 275: 90-94, 1997.

31. Turner-Ivey B, Manevich Y, Schulte J, Kistner-Griffin E, Jezierska-Drutel A, Liu Y and Neumann CA: Role for Prdx1 as a specific sensor in redox-regulated senescence in breast cancer. Oncogene 32: 5302-5314, 2013

32. Kim YJ, Lee WS, Ip C, Chae HZ, Park EM and Park YM: Prx1 supppresses radiation-induced c-Jun NH2-terminal kinase signaling in lung cancer cells through interaction with the glutathione S-transferase $\mathrm{Pi} / \mathrm{c}$-Jun NH2-termianl kinase complex. Cancer Res 66: 7136-7142, 2006.

33. Nakagawa H, Hirata Y, Takeda K, Hayakawa Y, Sato T, Kinoshita H, Sakamoto K, Nakata W, Hikiba Y, Omata M, et al: Apoptosis signal-regulating kinase 1 inhibits hepatocarcinogenesis by controlling the tumor-suppressing function of stress-activated mitogen-activated protein kinase. Hepatology 54: 185-195, 2011.

34. Yan W, Arai A, Aoki M, Ichijo H and Miura O: ASK1 is activated by arsenic trioxide in leukemic cells through accumulation of reactive oxygen species and may play a negative role in induction of apoptosis. Biochem Biophys Res Commun 355: 1038-1044, 2007.

35. Park JM, Greten FR, Li ZW and Karin M: Macrophage apoptosis by anthrax lethal factor through p38 MAP kinase inhibition. Science 297: 2048-2051, 2002.

36. Lee YJ, Song DS, Yoo JS, Hyung KE, Lee MJ, Moon YH, Lee IH, Go BS, Park SY and Hwang KW: Protective functionsm of peroxiredoxin-1 against cytokine-induced MIN6 pancreatic $\beta$-cell line death. Can J Physiol Pharmacol 91: 1037-1043, 2013.

37. Sun QK, Zhu JY, Wang W, Lv Y, Zhou HC, Yu JH, Xu GL, Ma JL, Zhong W and Jia WD: Diagnostic and prognostic significance of peroxiredoxin 1 expression in human hepatocellular carcinoma. Med Oncol 31: 786, 2014

38. Guo QJ, Mills JN, Bandurraga SG, Nogueira LM, Mason NJ, Camp ER, Larue AC, Turner DP and Findlay VJ: MicroRNA-510 promotes cell and tumor growth by targeting peroxiredoxin1 in breast cancer. Breast Cancer Res 15: R70, 2013.

39. Lennicke C, Rahn J, Lichtenfels R, Wessjohann LA and Seliger B: Hydrogen peroxide-production, fate and role in redox signaling of tumor cells. Cell Commun Signal 13: 39, 2015.

40. Min SK, Lee SK, Park JS, Lee J, Paeng JY, Lee SI, Lee HJ, Kim Y, Pae HO, Lee SK and Kim EC: Endoplasmic reticulum stress is involved inn hydrogen peroxide induced apoptosis in immortalized and malignant human oral keratinocytes. J Oral Pathol Med 37: 490-498, 2008.

41. Arima Y, Nishiqori C, Takeuchi T, Oka S, Morimoto K, Utani A and Miyachi Y: 4-Nitroquinoline 1-oxide forms 8-hydroxydeoxyguanosine in human fibroblasts through reactive oxygen species. Toxicol Sci 91: 382-392, 2006.

42. Tang XQ, Chen J, Tang EH, Feng JQ and Chen PX: Hydrogen peroxide preconditioning protects $\mathrm{PC} 12$ cells against apoptosis induced by oxidative stress. Sheng Li Xue Bao 57: 211-216, 2005.

43. Lee HT, Xu H, Ota-setlik A and Emala CW: Oxidant preconditioning protects human proximal tubular cells against lethal oxidant injury via p38 MAPK and heme oxygenase-1. Am J Nephrol 23: 324-333, 2003.

44. Lin B, Tan X, Liang J, Wu S, Liu J, Zhang Q and Zhu R: A reduction in reactive oxygen species contributes to dihydromyricetin-induced apoptosis in human hepatocellular carcinoma cells. Sci Rep 4: 7041, 2014. 